\title{
MONITORAMENTO DO VÍRUS DA RAIVA EM DIFERENTES ESPÉCIES DE MORCEGOS EM MARINGÁ, SUL DO BRASIL
}

\author{
Alexandre Luiz Polizel ${ }^{1}$ \\ Helena Beatriz de Carvalho Ruthner Batista ${ }^{2}$ \\ Henrique Ortêncio Filho ${ }^{3}$
}

\begin{abstract}
RESUMO
A raiva é uma enfermidade infectocontagiosa de caráter zoonótico, causada pelo vírus da raiva (RABV). Os quirópteros juntamente com os canídeos são os principais reservatórios do RABV, sendo responsáveis respectivamente pela manutenção dos ciclos aéreo e terrestre da doença. $\mathrm{O}$ presente trabalho teve por objetivo identificar interações entre o vírus e $\mathrm{o}$ reservatório no ciclo aéreo da raiva. Para isto, a presença do RABV foi investigada em amostras de saliva de morcegos de diferentes espécies. Foram realizadas trinta e seis capturas de morcegos, na Região de Maringá, Paraná, sul do Brasil, no período de abril a dezembro de 2013. Os morcegos foram capturados com auxílio de redes de nylon e acondicionados em sacos de algodão. Foram registrados os dados biométricos e coletada uma amostra de swab oral de cada exemplar. Para a identificação do RABV, foi realizada a técnica de Semi-Nested RT-PCR ("Reverse transcription polymerase chain reaction") tendo como alvo o gene N que codifica a nucleoproteína do vírus. A análise de dados foi realizada por estatística descritiva. Ao longo do estudo, foram capturados 444 morcegos, pertencentes a quatro famílias e quinze espécies. O RABV não foi identificado em nenhuma das amostras analisadas. Estes resultados demonstram a ausência de excreção do RABV pela saliva de morcegos saudáveis na região alvo do estudo e salientam para a necessidade de mais estudos sobre a manutenção da raiva nas diferentes espécies de morcegos.
\end{abstract}

Palavras-chave: chiroptera, vírus da raiva, saliva.

\section{RABIES VIRUS MONITORING IN DIFFERENT SPECIES OF BATS IN MARINGÁ, SOUTHERN BRAZIL}

\begin{abstract}
Rabies is an zoonotic infectious disease, caused by rabies virus (RABV). The bats with canids are the main RABV reservoirs, accounting respectively for maintaining the air cycles and terrestrial of the disease. This study aimed to identify interactions between the virus and the reservoir in air rabies cycle. For this, the presence of RABV was investigated in bat saliva samples from different species. Thirty-six capture bats were held in Maringá Region Parana, southern Brazil, from April to December 2013. The bats were captured with the help of nylon nets and placed in cotton bags. Were registered biometric data and collected a sample of oral swab of each especimen. For the identification of RABV, the semi-nested RT-PCR technique ("Reverse transcription polymerase chain reaction") targeting the $\mathrm{N}$ gene encodes the nucleoprotein of the virus was performed. Data analysis was performed using descriptive statistics. Throughout the study, were captured 444 bats belonging to four families and fifteen species. The RABV was not identified in the evaluated samples. These results demonstrate

\footnotetext{
${ }^{1}$ Graduando em Ciências Biológicas. Departamento de Biologia. Universidade Estadual de Maringá. Contato para correspondência.

2 Professora e Pesquisadora do Instituto Pasteur de São Paulo.

${ }^{3}$ Professor Doutor do Departamento de Ciências da Universidade Estadual de Maringá.
} 
the absence of excretion of RABV in the saliva of healthy bats in the studied area and reinforce the need for more studies about the maintenance of rabies in different species of bats.

Keywords: chiroptera, rabies vírus, saliva.

\title{
VIGILANCIA DE VIRUS DE LA RABIA EN ESPECIES DIFERENTES DE MURCIÉLAGOS EN MARINGÁ, SUR DE BRASIL
}

\begin{abstract}
RESUMEN
La rabia es una enfermedad infecciosa de zoonótica causada por el virus de la rabia (RABV). Los murciélagos con los cánidos son los principales reservorios RABV, que representan, respectivamente, para el mantenimiento de los ciclos de aire y terrestre de la enfermedad. Este estudio tuvo como objetivo identificar las interacciones entre el virus y el reservatório en el ciclo aéreo de la rabia. Para ello, la presencia de RABV se investigó en muestras de saliva de murciélago de diferentes especies. treinta y seis colecciones de murciélagos de hisopos orales se llevaron a cabo en Maringá Región Paraná, sur de Brasil, de abril a diciembre de 2013. Los murciélagos fueron capturadas con la ayuda de redes de nylon y se colocaron en bolsas de algodón eran registrado los datos biométricos y se recogió una muestra de hisopo bucal de cada individuo. Para la identificación de RABV, la técnica de semi-anidada RT-PCR ( "reacción en cadena de la polimerasa de transcripción inversa") en el gen $\mathrm{N}$ se realizó codifica la nucleoproteína del virus. El análisis de datos se realizó mediante estadística descriptiva. Durante todo el estudio, 444 murciélagos fueron capturados pertenecientes a cuatro familias y quince especies. El RABV no fue identificado en ninguna de las muestras. Estos resultados demuestran la ausencia de RABV en excreción de la saliva de los murciélagos sanos en el estudio de la región de destino y subrayan la necesidad de más estudios sobre la ira de mantenimiento en diferentes especies de murciélagos.
\end{abstract}

Palabras clave: chiroptera, virus de la rabia, saliva.

\section{INTRODUÇÃO}

A raiva é uma doença fatal de distribuição mundial que acomete todos os mamíferos, inclusive humanos. A principal forma de transmissão da doença é por meio de mordedura de animais infectados, apesar de já terem sido descritos casos de transmissão aérea e por transplantes de órgãos. O vírus da raiva (RABV) apresenta genoma RNA de fita simples e pertence à família Rhabdoviridae, gênero Lyssavirus (1).

Segundo Almeida et al. (2), em saúde pública, os morcegos são incriminados como transmissores de patógenos, visto que em todos os lugares do mundo há relatos de raiva transmitida por morcegos.

O primeiro caso de raiva identificado no Brasil em morcegos, foi registrado em 1921, por Haupt \& Rehaag, em um morcego frugívoro da espécie Artibeus planirostris, entretanto, poderia ser um morcego vampiro erroneamente identificado (3). Até o momento 41 espécies de morcegos não hematófagos já foram identificadas com o vírus da raiva no Brasil (4).

Apesar do morcego hematófago Desmodus rotundus ser o principal reservatório silvestre da raiva na América Latina, diversas espécies de morcegos não hematófagos já foram identificados com o RABV . O interesse pela busca do RABV nestes morcegos é crescente devido a adaptação destes ao ambiente urbano e ao seu comportamento sinantrópico podendo aumentar o risco de transmissão de doenças aos seres humanos $(5,6)$. Segundo Silva 
(7), a grande quantidade de insetos na zona urbana, resultado da iluminação artificial, aumenta a população de morcegos insetívoros nas cidades. A falta de abrigos naturais, decorrente do desmatamento, somada aos abrigos seguros nos ambientes urbanos, e a enorme concentração de insetos, criou para os quirópteros um ambiente propício para seu alojamento, especialmente, das espécies insetívoras, além disso, a ausência de predadores naturais também facilita a adaptação de morcegos no ambiente urbano $(2,8)$.

De acordo com Reis et al. (8) apesar da presença do RABV nos morcegos, assim como outros patógenos, os malefícios que os mesmos trazem são menores que os benefícios, pois eles têm importante papel no controle biológico de insetos (alguns destes também transmissores de patógenos), na polinização (realizada pelos morcegos nectarívoros) e, também, na dispersão de sementes ocasionada pelos morcegos frugívoros, aspectos relevantes em termos ambientais (9).

Apesar de ainda ocasionar a morte de aproximadamente 60.000 pessoas por ano, segundo a Organização Mundial da Saúde, o número de casos de raiva humana, no Brasil, esta em decréscimo, porém, vem sendo constatado aumento no registro de casos de quirópteros e outros animais silvestres infectados pelo RABV (5). Segundo o mesmo autor, ainda não há dados suficientes para concluir se este fato deve-se a um aumento na vigilância epidemiológica ou um aumento da prevalência da raiva nestas espécies.

Martorelli et al. (6), descreveram o comportamento de um morcego infectado pelo RABV, o qual mostrou-se anormal/diferenciado quando comparado com um saudável, por isto, geralmente, esses animais são encontrados caídos, dentro de imóveis, machucados, moribundos.

O conhecimento sobre o RABV tem avançado embora ainda são necessários mais estudos sobre a manutenção do vírus na natureza, principalmente em morcegos. Este trabalho teve por objetivo identificar o RABV na saliva de morcegos sadios de diferentes espécies.

\section{MATERIAL E MÉTODOS}

As amostras foram coletadas em fragmentos florestais localizados na área urbana do município de Maringá, Estado do Paraná, Região Sul do Brasil, no período de agosto de 2013 a janeiro de 2014, sob licença permanente para coleta de material biológico do Instituto Chico Mendes de Conservação da Biodiversidade - ICMBio (número: 17869-1, data da emissão: 05/02/2009) e certificação do Comitê de Conduta Ética no Uso de Animais em Experimentação (CEAE) da Universidade Estadual de Maringá.

Foram realizadas expedições mensais em diferentes locais de coleta, sendo que cada local foi visitado semanalmente em um dia randômico do mês. A partir desta seleção os locais de coleta foram:

Parque do Ingá: Unidade de Conservação urbana, localizada na região central do município de Maringá/PR, nas coordenadas geográficas $23^{\circ} 25^{\prime} 28^{\prime \prime S}$ e $51^{\circ} 55^{\prime} 59^{\prime \prime} \mathrm{O}$, com altitude de 557 metros e área de $474.300 \mathrm{~m}^{2}$.

Parque das Palmeiras: Área localizada entre a avenida São Judas Tadeu e a rua Flamboyant, nas coordenadas geográficas de $23^{\circ} 23^{\prime} 08^{\prime}$ 'S e 5156'21'O, com altitude de 499 metros e área de $61.434,48 \mathrm{~m}^{2}$.

Parque Florestal dos Pioneiros (Bosque II): Área localizada na região central de Maringá, nas coordenadas geográficas de $23^{\circ} 25^{\prime} 47^{\prime \prime} \mathrm{S}$ e $51^{\circ} 56^{\prime} 30^{\prime} \mathrm{O}$, com altitude de 524 metros e área de $594.400 \mathrm{~m}^{2}$.

Horto Florestal: O Horto Florestal Dr. Luiz Teixeira Mendes, localiza-se entre as coordenadas geográficas de $23^{\circ} 26^{\prime} 5^{\prime}$ 'S e $51^{\circ} 57^{\prime} 51^{\prime}$ 'O, altitude de 589 metros e área de $368.300 \mathrm{~m}^{2}$. 
Foram visitados, ainda 14 imóveis localizados na área urbana e um imóvel em área periurbana do município, de acordo com solicitação e agendamento dos proprietários dos mesmos.

Para a captura dos espécimes, foram utilizadas oito redes de nylon (mist-nest), conforme Greenhall e Paradiso (10) dispostas 30 metros de distância uma das outras. Nas residências, os morcegos foram coletados diretamente, por captura manual, conforme acesso ao forro. Quando o forro era inacessível, redes e puçás foram colocados nos locais de saída dos morcegos.

Os animais capturados foram contidos manualmente, e foram coletados os seguintes dados biométricos: medida de antebraço; gênero; peso e identificação taxonômica, conforme critérios de Vizotto e Taddei (11), Jones e Carter (12) e Gregorin e Taddei (13). As coletas foram realizadas por profissionais treinados, vacinados contra raiva no esquema de préexposição e utilizavam equipamentos de proteção individual.

A coleta de saliva foi realizada por meio de swab orofaríngeo individual. As amostras foram acondicionadas em microtubos individuais contendo Meio Essencial Mínimo (MEM) com antibiótico e antifúngico, mantidas sob refrigeração até o momento de processamento. A identificação do RNA viral do RABV foi realizada pela técnica de Semi-Nested RT-PCR ("Reverse Transcription Polymerase Chain Reaction"), tendo como alvo o gene N que codifica a nucleoproteína do vírus, conforme descrito por Carnieli et al. (14).

\section{RESULTADOS E DISCUSSÃO}

Foram realizadas 36 coletas durante o período do estudo, sendo 21 destas em fragmentos florestais e 15 em residências. A área abrangida em fragmentos florestais totalizou 28.800 h.m² (Fig 1).

Neste período, foram capturados 444 morcegos, pertencentes a quatro famílias e quinze espécies, conforme descrito a seguir: Família Phyllostomidae (Artibeus lituratus $\mathrm{n}=197$, Artibeus frimbriatus $\mathrm{n}=25$, Artibeus obscurus $\mathrm{n}=18$, Artibeus planirostris $\mathrm{n}=28$, Carollia perspicillata $\mathrm{n}=6$, Phyllostomus hastatus $\mathrm{n}=5$, Platyrrhinus lineatus $\mathrm{n}=5$, Sturnira lillium $\mathrm{n}=59$, Vampyressa pusilla $\mathrm{n}=2$ ), Família Vespertilionidae (Myotis nigricans $\mathrm{n}=2$, Myotis ruber $\mathrm{n}=1$ ), Família Molossidae (Molossus rufus $\mathrm{n}=61$, Molossus molossus $\mathrm{n}=30$, Molossops neglectus $\mathrm{n}=1$ ) e Família Noctilionidae (Noctilio leporinus $\mathrm{n}=4$ ). Não houve captura de exemplares de táxons ainda não catalogados para a região.

Das 444 amostras de saliva obtidas e submetidas à Semi-Nested RT-PCR, o RABV não foi identificado em nehuma delas. Os resultados obtidos neste estudo corroboram os dados da literatura, que descrevem baixa ocorrência de RABV, aproximadamente $1 \%$, em colônias de morcegos sadios. De acordo com Scheffer et al. (15) o percentual de morcegos infectados pela raiva, naturalmente, é de 1,9\%, já o trabalho de Almeida et al. (2) identificou, 0,69\% de morcegos positivos para o vírus rábico, no Centro de Controle de Zoonoses da Prefeitura do Município de São Paulo, área metropolitana da região Sudeste do Brasil.

Deve ser considerado ainda o fato de que estes percentuais são baseados na detecção de vírus no Sistema Nervoso Central (SNC) de morcegos enviados ao diagnóstico de raiva dos respectivos laboratórios, portanto são animais com suspeita clinica de raiva, que foram encontrados mortos ou ainda que fazem parte de algum programa de monitoramento de morcegos para o controle da raiva animal. Além disso, o SNC é a amostra padrão para diagnóstico de raiva em qualquer espécie (16), diferentemente da saliva. De acordo com a patogenia do RABV após a chegada do vírus ao SNC este é disseminado para o restante do organismo sendo a glândula salivar um dos primeiros órgãos atingidos (5). Apesar disso sabese que a disseminação do RABV na saliva ocorre de forma intermitente e, portanto, não é sempre detectável mesmo em animais doentes (17). 


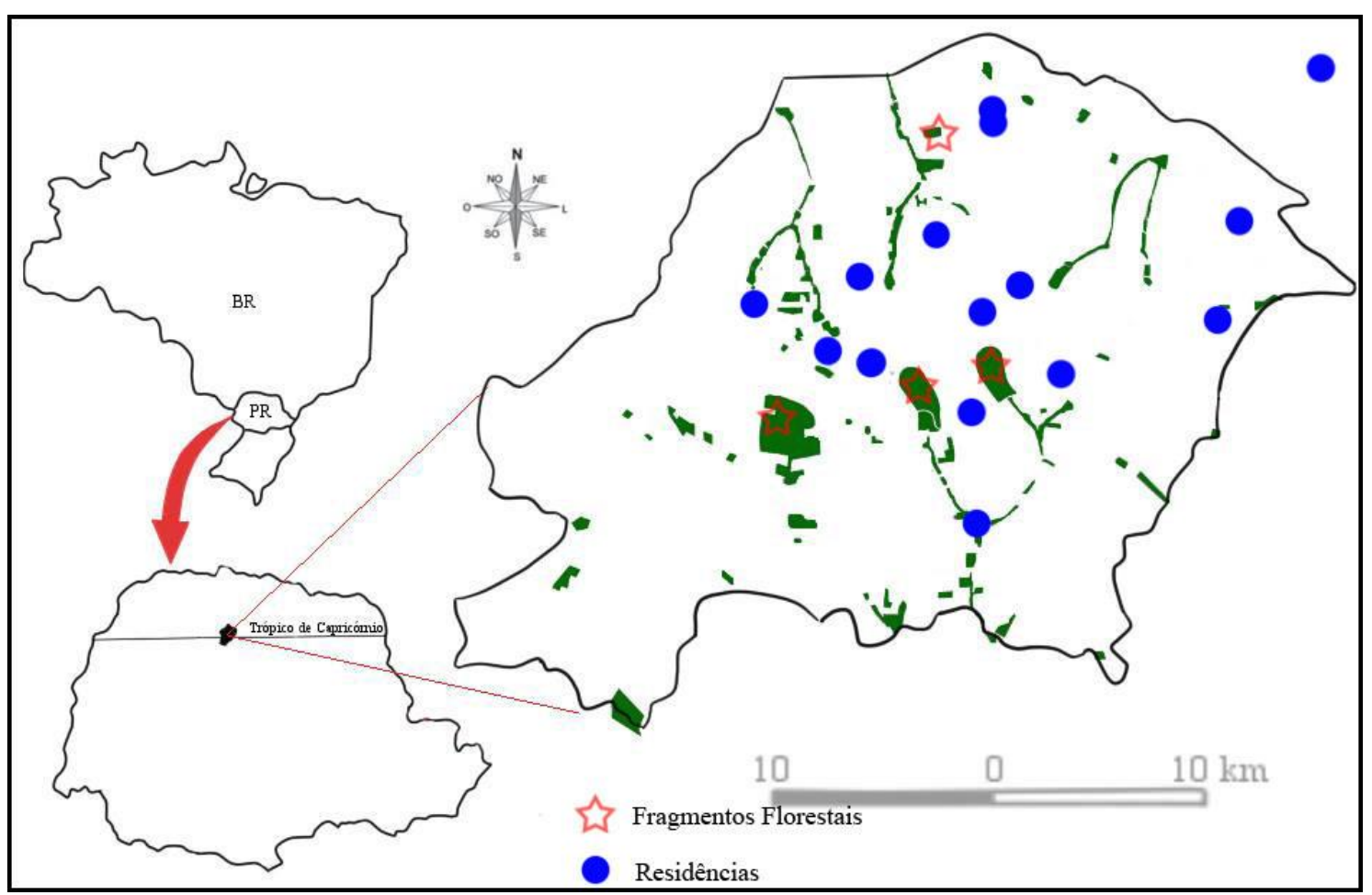

Figura 1. Pontos amostrais de morcegos capturados na região de Maringá, Paraná. Fonte: Arquivo Pessoal

Neste estudo foi utilizada a técnica de Semi-Nested RT-PCR, com alta sensibilidade e especificidade para identificação do RABV. Foram incluídos controles positivos e negativos em cada lote de amostras processadas eliminando possíveis resultados falsos positivos ou negativos. Harris et al. (17) desenvolveram um trabalho semelhante visando a vigilância ativa de Lyssavirus na Inglaterra entre os anos de 2003 a 2006. Foram analisadas 766 amostras de swab orofaríngeo contendo saliva de morcegos por meio de RT-PCR. Os mesmos não detectaram amostras de RNA viral nos animais, revelando não secreção viral via saliva no momento da amostragem. Schatz et al. (18) analisaram amostras de swabs orofaríngeos de morcegos na Alemanha no período de 1993 a 2012. Foram analisados 4546 morcegos distribuídos em 24 espécies. Deste total, apenas sete foram positivos por RT-PCR, a saber: Eupean bat lyssavirus 1 (EBLV-1) também membro do gênero Lyssavirus, Barbastella barbastelus $(\mathrm{n}=1)$, Eptesicus serotinus $(\mathrm{n}=5)$ e Myotis nattereri $(\mathrm{n}=1)$. Os mesmos autores discutem ainda que a utilização da biologia molecular para o conhecimento da dinâmica da raiva e vigilância das colônias de morcegos mostra-se essencial na epidemiologia da raiva.

Echeverría et al. (19) analisaram amostras de 75 morcegos E. serotinus, no período de junho de 1999 a agosto de 2000. Todos os exemplares encontravam-se na mesma colônia em um edifício publico de Sevilha, Espanha. Os pesquisadores utilizaram amostras de saliva coletadas por $s w a b$ orofaríngeo, conservados em MEM e submetidos a RT-PCR. O EBLV-1 foi identificado em 15 morcegos, sendo: setembro/1999 ( $n=1)$, maio/2000 ( $n=4)$ e em junho/2000 $(n=10)$. Nos demais meses, o vírus não foi identificado no exsudato orofaríngeo em nenhum animal. Destaca-se que a análise molecular da saliva representa uma importante ferramenta para a vigilância epidemiológica do vírus da raiva, sendo também uma importante ferramenta de conservação e manejo, visto que permite não apenas a detecção, mas possibilita manter os espécimes possivelmente negativos vivos. 


\section{CONCLUSÃO}

O RABV não foi identificado em nenhuma das amostras analisadas. Estes resultados demonstram a baixa taxa de infecção pelo RABV em morcegos saudáveis nas regiões avaliadas, o que contribui para a baixa dispersão viral nesses locais.

\section{AGRADECIMENTOS}

Ao suporte financeiro fornecido pelas instituições: CAPES/CNPQ, Fundação Araucária e Instituto Pasteur de São Paulo.

\section{REFERÊNCIAS}

1. International Committee on Taxonomy of Viruses. The Universal Virus Database, version 4 [Internet]. Ithaca, New York. 2016 [cited 2016 Mar 23]. Available from://www.ncbi.nlm.nih.gov/ICTVdb/ICTVdB/

2. Almeida MF, Aguiar EAC, Martorelli LFA, Silva MMS. Diagnóstico laboratorial de raiva em quirópteros realizado em área metropolitana na região sudeste do Brasil. Rev Saude Publica. 1994;28(5):341-4.

3. Silva LHQ, Cunha EMSC, Pedro WA, Cardoso TC, Souza MCC, Ferrari CIL. Isolamento do vírus rábico em Molossus ater (Chiroptera: Molossidae) no Estado de São Paulo. Rev Saude Publica. 1999;33(6):626-8.

4. Sodré MM, Gama AR, Almeida MF. Updated list of bat species positive for rabies in Brazil. Rev Inst Med Trop São Paulo. 2010;52:75-81.

5. Batista HBCR, Franco AC, Roeche PM. Raiva: uma breve revisão. Acta Sci Vet. 2007;35(2):125-44.

6. Martorelli LFA, Aguiar EAC, Almeida MF, Silva MMS, Nunes VFP. Isolamento do vírus rábico de morcego insetívoro, Lasiurus borealis. Rev Saude Publica. 1996;30(1):101-2

7. Silva MMS, Harman I, Gonçalves EFB, Uieda V. Bats from the metropolitan region of São Paulo, southeastern Brazil. Chiropt Neotrop. 1996;2(1):39-41.

8. Reis NR, Lima IP, Peracchi AL. Morcegos (Chiroptera) da área urbana de Londrina, Paraná, Brasil. Rev Bras Zool. 2006;19(3):739-46.

9. Mikich SB. A dieta dos morcegos frugívoros (Mammalia, Chiroptera, Phyllostomidae) de um pequeno remanescente de floresta estacional semidecidual do sul do Brasil. Rev Bras Zool. 2002;19(1):239-49.

10. Grenhall AM, Paradiso JL. Bats and bat banding. Washington: Bureau of Sport Fisheries and Wild; 1968.

11. Vizotto LD, Taddei VA. Chave para determinação de quirópteros brasileiros. Bol Cienc. 1973;1:1-72. 
12. Jones Jr JK, Carter DC. Annotated checklist, with keys to subfamilies and genera. In: Baker RJ, Jones Jr JK, Carter DC. Special Publications Museum Texas Tech. University. Biology of bats of the new world family Phyllostomidae. Part I. Lubbock: Texas Tech Press; 1976. v.10, p.7-38.

13. Gregorin R, Taddei VA. Chave artificial para identificação de molossídeos brasileiros (Mammalia, Chiroptera). Mastozool Neotrop. 2002;1(9):13-32.

14. Carnieli JRP, Fahl WO, Castilho JG, Oliveira RN, Macedo CI, Durymanova E, et al. Characterization of Rabies virus isolated from canids and identification of the main wild canid host in Northeastern Brazil. Virus Res. 2008;131:33-46.

15. Scheffer KC, Carrieri ML, Albas A, Santos HCP, Kotait I, Ito FH. Vírus da raiva em quirópteros naturalmente infectados no Estado de São Paulo, Brasil. Rev Saude Publica. 2007;41(3):389-95.

16. World Health Organization. Expert Committee on Rabies, 8th Report. Geneve: WHO; 1992. (Technical report series, $\mathrm{n}^{\mathbf{o}} 824$ ).

17. Harris SL, Aegerter JN, Brookes SM, Mcelhinney LM, Jones G, Smith GC, et al. Targeted surveillance for european bat Lyssaviruses in english bats (2003-06). J Wildl Dis. 2009;45(4):1030-41.

18. Schatz J, Ohlendorf B, Busse P, Pelz G, Dolch D, Theubner J, et al. Twenty years of active bat rabies surveillance in Germany: a detailed analysis and future perspectives. Epidemiol Infect. 2014;142(6):1155-66.

19. Echevarria JE, Avellón A, Juste J, Vera M, Ibánez C. Screening of active Lyssavirus infection in wild bat populations by viral RNA detection on oropharyngeal swabs. J Clin. 2001;10(39):3678-83.

Recebido em: 01/08/2016 Aceito em: 19/08/2017 